\title{
Direct PCR-free electrochemical biosensing of plant- food derived nucleic acids in genomic DNA extracts. Application to the determination of the key allergen Sola 17 in tomato seeds
}

\author{
Magda A.Pereira-Barros \\ M. Fátima Barroso \\ Laura Martín-Pedraza \\ Eva Vargas \\ Sara Benedé \\ Mayte Villalba \\ João M. Rocha \\ Susana Campuzano \\ José M. Pingarróna
}

\section{Abstract}

A novel and disposable electrochemical biosensor for PCR-free and selective detection of Sola 17, a non-specific lipid transfer protein (nsLTP) found in tomato seeds associated to severe symptoms of tomato-allergic patients, is reported in this work. The methodology involves the formation of DNA/RNA heterohybrids by sandwich hybridization of a specific fragment of the Sola 17 allergen coding sequence with appropriate RNA probes designed and described for the first time in this work. Labeling was carried out with commercial antibodies specific to the heteroduplexes and secondary antibodies conjugated with HRP onto the surface of magnetic beads. Amperometric transduction was performed upon magnetic capture of the resulting magnetic bioconjugates on screenprinted electrodes using the system $\mathrm{H}_{2} \mathrm{O}_{2} / \mathrm{HQ}$. A comparison of the sandwich hybridization format with a direct approach as well as between different labeling strategies was performed. The LOD value achieved was $0.2 \mathrm{pM}$ ( 5 amol in $25 \mu \mathrm{L})$. The biosensor was successfully applied to the selective analysis of the targeted Sola $l 7$ specific region directly in just $100 \mathrm{ng}$ of non-fragmented denatured genomic DNA extracted from tomato seeds.

\section{Keywords}

Sola 17 allergen coding-sequences

Sandwich hybridization

AbRNA/DNA

Screen-printed electrodes

Amperometry

Genomic DNA extract 


\section{Introduction}

Food allergy is gradually growing worldwide and is one of the major current health concerns (Eissa et al., 2013), (Martín-Pedraza et al., 2016). The presence of hidden allergens in food, by unintentional cross-contamination or non-accurate labelling, is of great importance for both allergic consumers and producers (Zurzolo et al., 2012). Therefore, highly specific and sensitive analytical methods able to detect traces of these allergens in a rapid, robust, reliable, end-user friendly and cost-effective way are highly demanded for ensuring the compliance of food labeling and improving consumer protection (Ruiz-Valdepeñas Montiel et al., 2016).

Vegetal origin allergens are especially relevant because they affect approximately $2-4 \%$ of the European adult population (Asero, 2013). Among them, tomato (Solanum lycopersicum), one of the most consumed vegetables worldwide both as fresh and processed food (Martín-Pedraza et al., 2016), has been claimed as a prevalent plantderived food sensitizer (Larramendi et al., 2008), (Bassler et al., 2009) with an allergenic frequency ranging between 1.5 and $20 \%$ in different populations of patients with specific IgE (Ballmer-Weber and Hoffmann-Sommergruber, 2011), (Geroldinger-Simic et al., 2011). Particularly, 6.5\% of this allergic population is sensitized to tomato fruit in the Spanish Mediterranean region although $80 \%$ of these patients still tolerated its consumption. Recent studies have demonstrated that the non-specific lipid transfer protein (nsLTP) Sola 17 is the most allergenic protein in tomato seeds. This allergenic protein, very stable and found in numerous occasions masked in some commercial foods and sauces, causes severe and unexpected reactions, including anaphylaxis (MartínPedraza et al., 2016). Therefore, its presence in food is a major concern for the food industry and food-allergic consumers.

Currently, the main methods to detect traces of food allergens focus on testing allergic proteins by SDS-PAGE, immunoblotting, ELISA, dipstick assays, or detecting specific fragments of genes encoding the target allergens usually by conventional, real-time, digital PCR, microarray or PCR-ELISA. However, commercial production processes involve heat treatment and/or high-pressure industrial practices which often destroy partially or totally the tertiary structure of food proteins despite the high stability of many of them, and hence cannot be detected using conventional techniques (Arlorio et al., 2007), (Sun et al., 2012), (Iniesto et al., 2013). Therefore, methods based on detecting specific DNA fragments are advantageous because DNA remains intact longer under heat and pressure processing, shows constant concentrations and sequence conserved within all species and allows better extraction yields (even from processed and heat-treated samples) (Santiago-Felipe et al., 2014). However, conventional PCR methods may fail when longer DNA targets are broken down to small fragments during extensive food processing (Ali et al., 2012) and require the use of external standards, these hindering the application of such methods to processed foods or complex food matrices (Holzhauser et al., 2014). In this context, PCR amplification strategies coupled to electrochemical nucleic acid biosensing methodologies have been proposed to determine specific fragments of characteristic allergen coding sequences (Bettazzi et al., 2008), (RuizValdepeñas Montiel et al., 2017a). These strategies offer a convenient and flexible alternative tool to conventional PCR-based methodologies and combine the high selectivity and sensitivity of nucleic acid amplification strategies with the advantages provided by electrochemical sensors in food analysis (Mishra et al., 2018) such as user friendliness, multiplexing capabilities, quantitative results and suitability to fabricate 
compact and low cost devices. Moreover, to develop strategies of easy implementation in portable devices to perform routine determinations at decentralized settings, isothermal nucleic acid amplification strategies have been used together with electrochemical sensors (Barreda Garcia et al., 2015), (Li et al., 2015), (Barreda Garcia et al., 2016), (Torrente-Rodríguez et al., 2016), (Barreda Garcia et al., 2017), (Jirakova et al., 2019). Despite the attractive characteristics provided by these strategies, the design of affordable, quick and simple nucleic acid electrochemical biosensors enable achieving the required sensitivity without involving the use of nanomaterials and/or target nucleic acid amplification strategies is still a practical challenge (Ruiz-Valdepeñas Montiel et al., 2018).

Recent results reported by Pingarrón's group have shown the possibility of achieving significant and tunable amplification by exploring novel assay configurations and labeling strategies leading to larger biomolecule or multienzyme loadings on appropriate detector bioreceptors (oligonucleotides or specific antibodies) (Ruiz-Valdepeñas Montiel et al., 2018). Indeed, an attractive electroanalytical platform involving direct hybridization assay onto magnetic microbeads (MBs) and amperometric transduction at screen-printed carbon electrodes (SPCEs) using the system $\mathrm{HRP} / \mathrm{H}_{2} \mathrm{O}_{2} / \mathrm{HQ}$, was constructed to detect unequivocally the presence of horsemeat without nucleic acid amplification by targeting a specific region of its D-loop mitochondrial genome directly in raw mitochondrial lysates. The method was based on the efficient capture of the target mitochondrial DNA on streptavidin-functionalized magnetic microcarriers previously modified with a specific biotinylated RNA probe. The resulting heteroduplexes immobilized on the MBs were labeled with a specific DNA-RNA antibody (Ab RNA/DNA $_{\text {) }}$ previously incubated with Protein A conjugated with a homopolymer containing 40 units of HRP (Ruiz-Valdepeñas Montiel et al., 2017b).

Considering these recent findings, this work reports the first electrochemical nucleic acid biosensor for the sensitive and selective determination of the Sola 17 allergen by targeting a 60-mer specific fragment of its coding sequence in tomato seeds. The method implies a specific DNA/RNA sandwich hybridization coupled to the use of antibodies specific to the formed heterohybrids further conjugated with HRP-labeled secondary antibodies (anti-IgG-HRP). These affinity reactions were implemented on the surface of MBs while the amperometric transduction was carried out at SPCEs using the system $\mathrm{H}_{2} \mathrm{O}_{2} / \mathrm{HQ}$. The optimized biosensing platform exhibited a great performance for the analysis of nonfragmented genomic DNA (gDNA) extracted from tomato fruits. Importantly, this target DNA has smaller copies and is much longer than that determined in (Ruiz-Valdepeñas Montiel et al., 2017b).

\section{Materials and methods}

\subsection{Apparatus and electrodes}

Amperometric measurements were performed with a $\mathrm{CH}$ Instruments (Austin, TX) model 812B potentiostat controlled by software CHI812B. Screen-printed carbon electrodes (SPCEs) (DRP-110, DropSens, Spain) used as electrochemical transducers in conjunction with a specific cable connector (DRP-CAC, DropSens), consisted of a 4-mm diameter carbon working electrode, a carbon counter electrode and an Ag pseudo-reference electrode. A homemade Teflon casing with a neodymium magnet (AIMAN GZ) embedded and placed just below the working electrode, once the SPCE was set on the 
casing, was used to magnetically capture in a reproducible way the modified-MBs on the surface of the SPCE. All measurements were made at room temperature.

An incubator shaker Optic Ivymen ${ }^{\circledR}$ System (Comecta S.A, Sharlab), a biological safety cabinet Telstar Biostar, a Raypa steam sterilizer, a thermocycler (SensoQuest LabCycler, Progen Scientific Ltd.), a Bunsen AGT-9 Vortex for homogenization of the solutions, a magnetic particle concentrator DynaMagTM-2 (123.21D, Invitrogen Dynal AS), a stove (CH-100, Boeco), a centrifuge MiniSpin ${ }^{\circledR}$ Eppendorf, a Powerpac ${ }^{\mathrm{TM}} \mathrm{HV}$ high-voltage power supply (BIO-RAD) and a spectrophotometer NanoDrop ND-1000 ${ }^{\circledR}$ were also employed.

\subsection{Reagents, solutions and samples}

All reagents used were of the highest analytical grade. Streptavidin-modified magnetic microbeads (Strep-MBs, $2.8 \mu \mathrm{m} \varnothing, 10 \mathrm{mg} \mathrm{mL}^{-1}$, Dynabeads M-280 Streptavidin, 11206D) were purchased from Dynal Biotech ASA.

Sodium chloride, potassium chloride, sodium dihydrogen phosphate, disodium hydrogen phosphate, and Tris-hydroxymethyl aminomethane- $\mathrm{HCl}$ (Tris- $\mathrm{HCl}$ ) were purchased from Scharlab. Protein A-HRP conjugate (ProtA-HRP, stock concentration of $1 \mathrm{mg} \mathrm{mL} \mathrm{m}^{-1}$ after solid reconstitution), hydroquinone (HQ) and hydrogen peroxide (30\%, w/v) were purchased from Sigma-Aldrich. Ethylenediaminetetraacetic acid (EDTA) from Merck

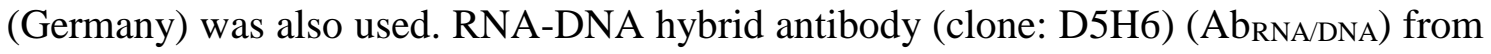
Covalab and HRP-labeled antimouse IgG Fc (antiIgG-HRP) from Abcam were also used.

A blocker casein solution (a ready to use, PBS solution of $1 \% \mathrm{w} / \mathrm{v}$ purified casein) was purchased from Thermo Scientific. All the oligonucleotides used (probes, synthetic target and mismatched and non-complementary sequences), whose sequences are described in Table S1 in the Supporting Information, were purchased from Sigma-Aldrich. Upon reception, they were reconstituted in nuclease free water to a final concentration of $100 \mu \mathrm{M}$, divided into small aliquots and stored at $-20^{\circ} \mathrm{C}$.

All the buffer solutions were prepared in deionized water obtained from a Millipore MilliQ purification system $(18.2 \mathrm{M} \Omega \mathrm{cm})$ and sterilized after their preparation: $0.05 \mathrm{~mol} \mathrm{~L}^{-1}$ phosphate buffer, $\mathrm{pH} 6.0$ and Binding and Washing buffer (B\&W) consisting of $10 \mathrm{mM}$ Tris- $\mathrm{HCl}$ solution containing $1 \mathrm{mM}$ EDTA and $2 \mathrm{M} \mathrm{NaCl}, \mathrm{pH}$ 7.5.

Agarose (Laboratorios Conda) and a NucleoSpin ${ }^{\circledR}$ Plant II kit (Ref: 740770.50, MACHEREY-NAGEL), including hexadecyltrimethylammonium bromide (CTAB), SDS, RNase A, guanidine hydrochloride, NucleoSpin columns, 2-propanol, and elution buffer Tris/ $\mathrm{HCl}$ were used for the gDNA extraction.

Tomato and corn samples were purchased in a local supermarket.

Details about all the protocols used (Genomic DNA extraction, Fig. S1, Preparation of the amperometric genosensor and functionalization of $\mathrm{MBs}$ and Amperometric measurements) are described in detail in the Supporting information. 


\section{Results and discussion}

A schematic display of the fundamentals involved in the nucleic acid biosensing platform prepared for the determination of a specific fragment of the Sola $l 7$ allergen coding sequence is shown in Fig. 1. In brief, magnetic microcarriers modified with a specific bRNACp were used to selectively capture the synthetic target DNA (or the denatured gDNA extracted) which was further hybridized with a specific RNA detector probe (RNADp). The resulting sandwiched 60-bp-RNA/DNA heterohybrids attached to the MBs were recognized by specific DNA-RNA antibodies (Ab $b_{\text {RNA/DNA }}$ with a binding epitope of about 6 bp in size (Qavi et al., 2011)) previously labeled with secondary antibodies conjugated with HRP (anti-IgG-HRP). The as prepared MBs with the sandwich RNA/DNA heterohybrids captured and bearing a large number of HRP molecules, were magnetically captured on the SPCE working electrode surface previously placed on a custom-fabricated magnetic holding block. The extent of the affinity reactions was detected by amperometry at $-0.20 \mathrm{~V}$ (vs the Ag. pseudoreference electrode) in stirred solutions using the system $\mathrm{H}_{2} \mathrm{O}_{2} / \mathrm{HQ}$ (both the detection potential and the $\mathrm{H}_{2} \mathrm{O}_{2} / \mathrm{HQ}$ concentrations were previously optimized for the $\mathrm{HQ} / \mathrm{HRP} / \mathrm{H}_{2} \mathrm{O}_{2}$ system (Eguílaz et al., 2010), (Gamella et al., 2012)). The measured cathodic current is due to the HRP reduction of $\mathrm{H}_{2} \mathrm{O}_{2}$ mediated by $\mathrm{HQ}$ (see scheme reaction in Fig. 1) (Volpe et al., 1998), (Camacho et al., 2007) where the oxidized form of the mediator, benzoquinone (BQ), was reduced at the applied detection potential on the electrode surface providing a cathodic current proportional to the concentration of the target DNA concentration.

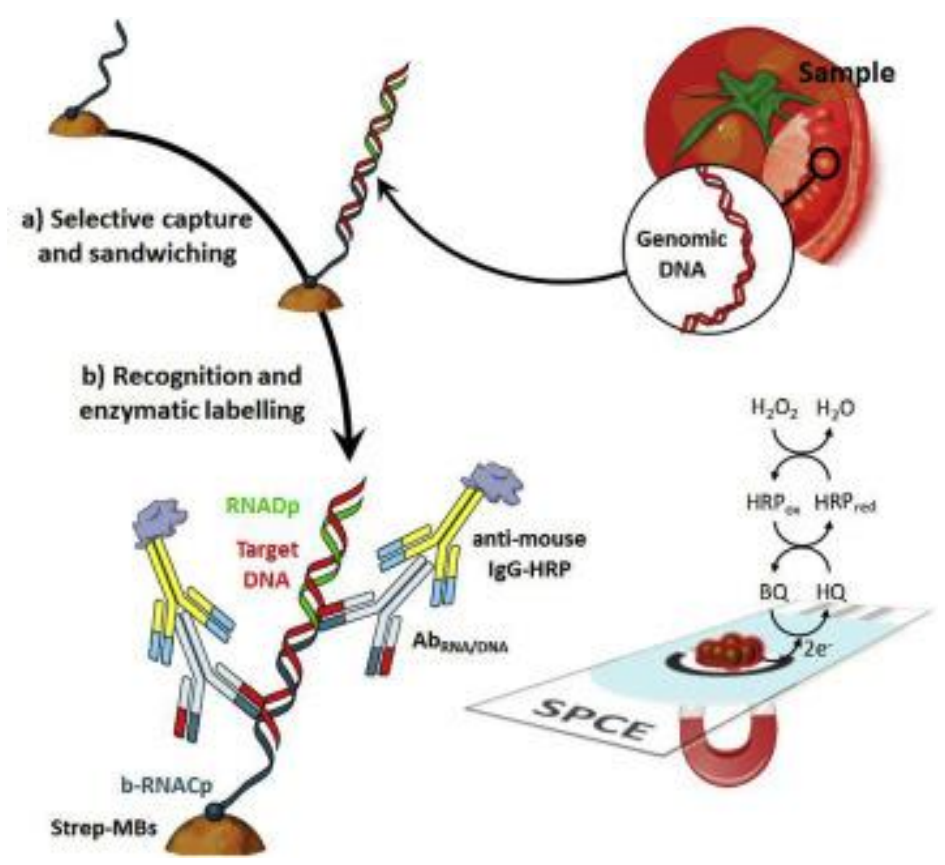

Fig. 1. Schematic display of the MBs-based amperometric biosensing strategy developed at SPCEs for targeting a specific fragment of the Sola 17 allergen coding sequence.

\subsection{Optimization of experimental variables}

Most of the experimental variables involved in the biosensor functioning were optimized taking as the selection criterion the largest ratio between the amperometric signals 
measured at $-0.20 \mathrm{~V}$ ( $v s$. the Ag pseudoreference electrode) for 0 (blank, B) and $50 \mathrm{pM}$ of synthetic target DNA (signal, S) (signal-to-blank, S/B, ratio) (Fig. 2).
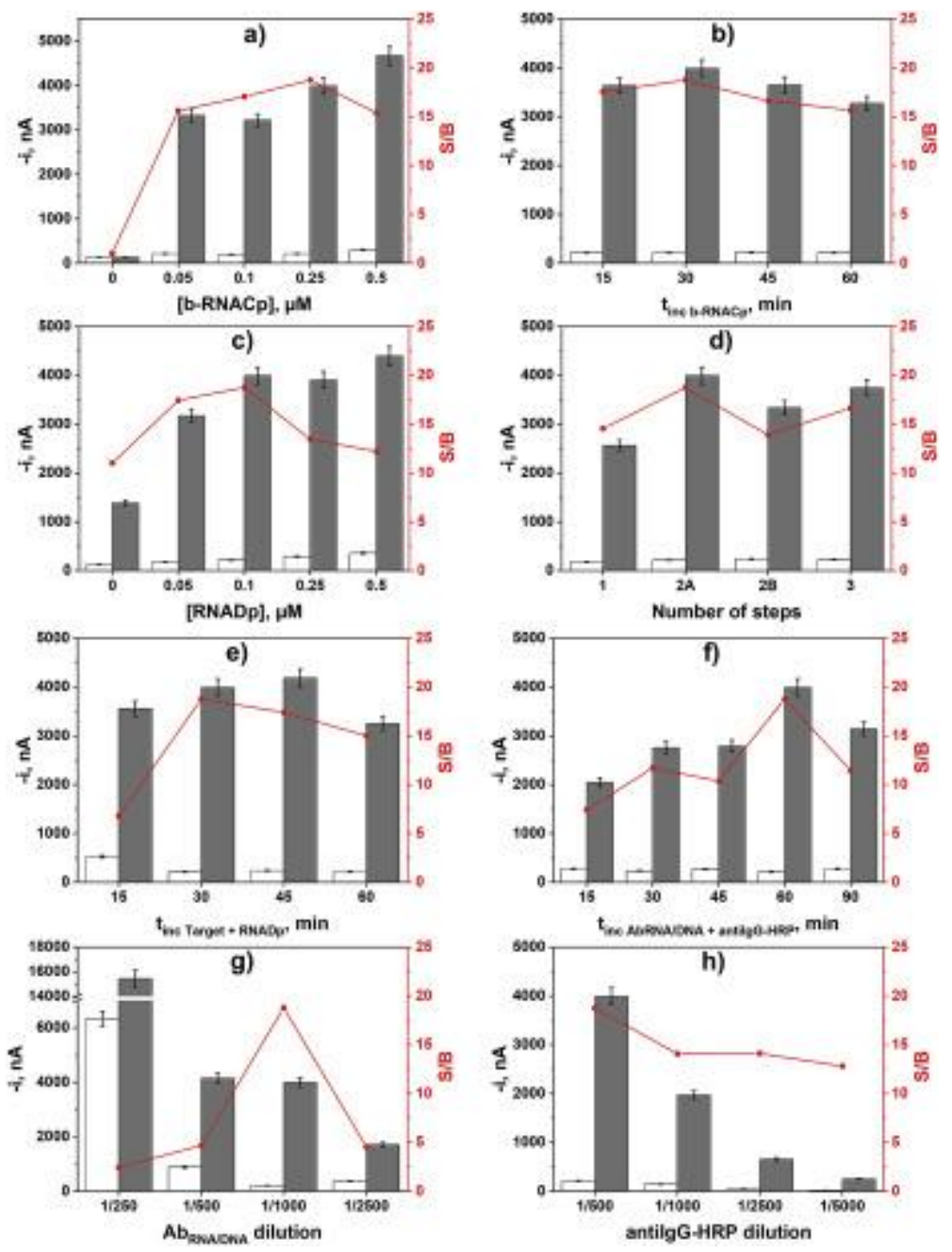

Fig. 2. Optimization of the experimental variables involved in the preparation of Sola 17 amperometric biosensors. Dependence of the amperometric responses measured for 0 (blank, B, white bars) and $50 \mathrm{pM}$ of synthetic target DNA (signal, S, grey bars) specific to the Sola $l 7$ allergen coding sequence, and the corresponding S/B ratio values (red circles) with the b-RNACp concentration (a), incubation time of the Strep-MBs on the bRNACp solution (b), RNADp concentration (c), number of steps involved in the protocol (d), incubation times in the mixture solutions containing the target DNA and RNADp (e), and $A b_{\text {RNA/DNA }}$ and anti-IgG-HRP (f), concentration of AbRNA/DNA (g) and antiIgG-HRP (h). Amperometric detection at $-0.20 \mathrm{~V}$ ( $v s$. Ag pseudoreference electrode) at SPCEs. Error bars were estimated as triple of the standard deviation $(n=3)$. (For interpretation of the references to colour in this figure legend, the reader is referred to the Web version of this article.)

Results obtained using direct hybridization of the $60 \mathrm{nt}$-selected target with just a capture probe of $30 \mathrm{nt}$ were compared with those provided by a sandwich-type hybridization configuration involving, in addition to the same capture probe, a detection probe of $30 \mathrm{nt}$. The sandwich-type hybridization format provided a 5.6-times higher sensitivity (calibration curve slope), compared to the direct hybridization strategy (in the absence of detector probe). These experimental results (displayed in Fig. S2 in the Supporting 
Information) are in agreement with that expected considering that the binding epitope of the Ab $b_{\text {RNA/DNA }}$ is about 6-bp in size (Qavi et al., 2011). In this particular case, since there were 30 additional nucleotides, ideally there should be 5 additional Ab attached to each single 60 bp-heterohybrid which is consistent with the achieved amplification factor. This finding opens the possibility of tailoring the sensitivity of the assay by varying the heterohybrid length.

In addition, the analytical performance exhibited by biosensors based on the sandwich hybridization using the secondary antibody (anti-IgG-HRP) or a bacterial immunoglobulin-binding (Protein A) conjugated with HRP (ProtA-HRP dil. 1/1000 (Ruiz-Valdepeñas Montiel et al., 2018)) to label the AbRNA/DNA was also compared. Both methodologies provided attractive analytical characteristics using simple protocols with no need for the use of nanomaterials or strategies to amplify the target DNA. Nevertheless, a 5.4-times higher sensitivity was achieved using the secondary antibody compared to the Protein A (see Fig. 3). These results are in agreement with previous reports (Ruiz-Valdepeñas Montiel et al., 2018) and are attributed to a better affinity of the antiIgG-HRP for the AbRNA/DNA than the ProtA-HRP.

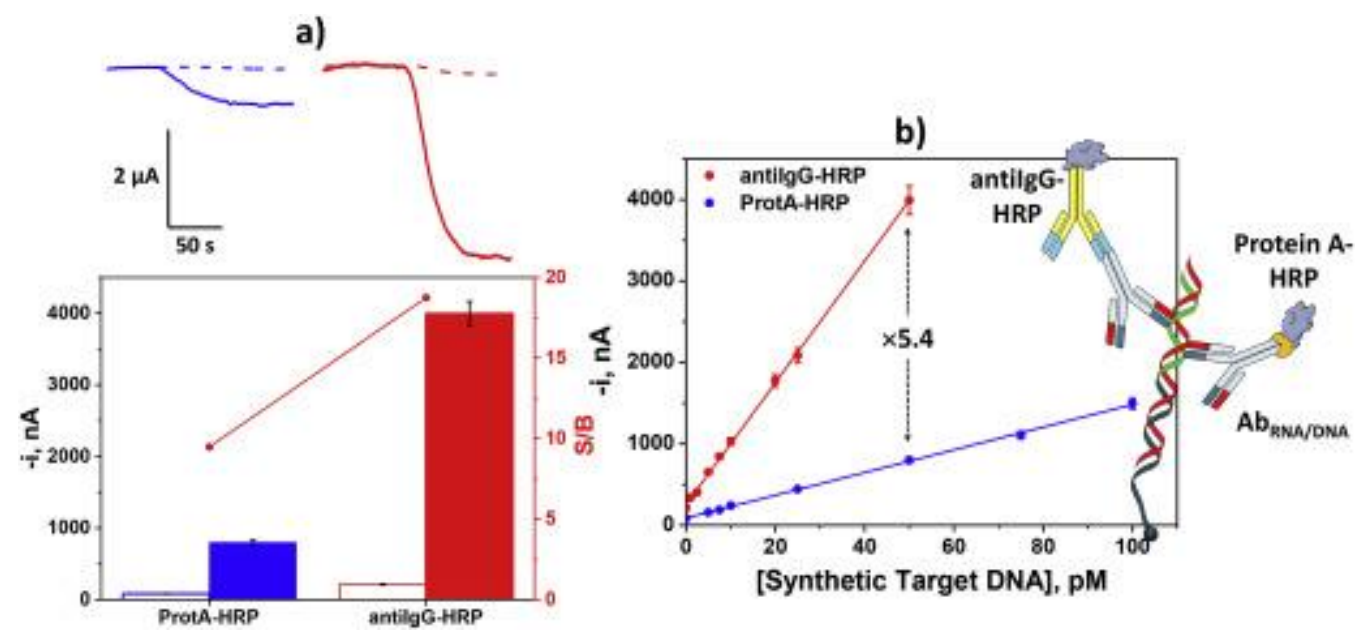

Fig. 3. Comparison of the amperometric responses and amperograms recorded for 0 (dashed lines and empty bars) and $50 \mathrm{pM}$ (solid lines and full bars) target DNA with

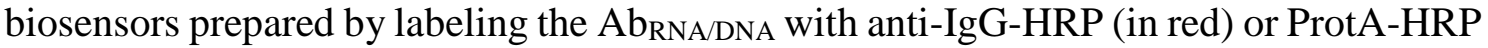
(in blue) (a). Calibration plots constructed for the amperometric determination of the Sola $l 7$ allergen coding sequence using both labeling strategies (b). Amperometric detection performed at $-0.20 \mathrm{~V}$ (vs. Ag pseudoreference electrode) with SPCEs. Error bars are 3 times the standard deviation of three replicates. (For interpretation of the references to colour in this figure legend, the reader is referred to the Web version of this article.)

Accordingly, a sandwich assay format and an Ab $b_{\text {RNA/DNA }}$ labeling with antiIgG-HRP was selected for further work.

Regarding the other experimental variables involved, Fig. 2a) and c) show that the S/B ratios increased with the concentration of the capture (b-RNACp) and detection (RNADp) probes up to 0.25 and $0.1 \mu \mathrm{M}$ values, respectively, and decreased with larger concentrations most likely due to the restricted hybridization efficiency when large amounts of probes are used (Liu et al., 2014), (Zouari et al., 2018). Fig. 2b) shows that 
30 min were enough to allow the efficient b-RNACp immobilization on the Strep-MBs to ensure an effective hybridization.

A relevant optimization study in order to develop simpler and shorter assay protocols is the one on the number of steps involved in the biosensor preparation. Accordingly, the amperometric responses measured with biosensors prepared using the following protocols (all of them with incubation steps of $30 \mathrm{~min}$ and starting from the b-RNACpMBs) were compared:

Protocol 1: one incubation step with a mixture solution containing the target DNA, RNADp, Ab $b_{\text {RNA/DNA }}$ and antiIgG-HRP.

Protocol 2A: two sequential incubation steps with solutions containing (1) the target DNA and RNADp and (2) AbRNA/DNA and antiIgG-HRP.

Protocol 2B: 2 sequential incubation steps with (1) the target DNA and with (2) a mixture solution containing RNADp, Ab $b_{\text {RNA/DNA }}$ and anti-IgG-HRP.

Protocol 3: three sequential incubation steps with the (1) target DNA, (2) RNADp and with (3) a mixture solution containing Ab RNA/DNA $_{\text {and anti-IgG-HRP. }}$

Fig. 2d) shows as the protocol 2A provided better S/B ratio and, therefore, was selected for the construction of the biosensors fabrication. These results can be attributed to the improved efficiency of the hybridization reaction of the target DNA with RNADp and the labeling of $A b_{\text {RNA/DNA }}$ with anti-IgG-HRP in homogeneous solutions.

The time required for the two incubation steps (Fig. 2e) and f)) as well as the Ab $b_{\text {RNA/DNA }}$ and antiIgG-HRP concentrations were also optimized (Fig. 2g) and h)). Table 1 summarizes all the selected experimental variables as well as the ranges in which these variables were optimized.

Table 1. Optimization of the different experimental variables involved in the preparation of biosensors for the amperometric determination of Sola 17 coding sequence.

\section{Variable}

Strep-MBs suspension, $\mu \mathrm{L}$

[b-RNACp], $\mu \mathrm{M}$

tinc b-RNACp, min

Number of steps

[RNADp], $\mu \mathrm{M}$

\section{Tested range Selected value}

5

$0-0.5 \quad 0.25$

$0-60 \quad 30$

1-3 2A

0-0.5 $\quad$ 0.1


Variable

$t_{\text {inc target DNA+RNADp }}, \min$

$t_{\text {inc }}$ AbRNA/DNA + antilgG-HRP, min 15-90

AbrNA/DNA dilution

antiIgG-HRP dilution

\section{Tested range Selected value}

$0-60$

30

60

$1 / 2500-1 / 250$ 1/1000

$1 / 5000-1 / 500$ 1/500

\subsection{Analytical characteristics}

The analytical performance of the developed biosensor was tested using the $60 \mathrm{nt}-$ synthetic target DNA. Under the selected experimental conditions, the obtained calibration plot is displayed in Fig. 3 (calibration in red). A linear relationship $(r=0.9988)$ between the measured cathodic current and the target DNA concentration was found in the $0.8-50 \mathrm{pM}$ range, with slope and intercept values of $(74,794 \pm 1677) \mathrm{nA} \mathrm{nM}^{-1}$ and $(254 \pm 34) \mathrm{nA}$, respectively. The detection (LOD) and quantification (LQ) limits were calculated according to the $3 \times \mathrm{sb} / \mathrm{m}$ and $10 \times \mathrm{sb} / \mathrm{m}$ criteria, respectively, where $\mathrm{m}$ is the slope value of the linear calibration plot and $\mathrm{s}_{\mathrm{b}}$ was estimated as the standard deviation of ten amperometric measurements made in the absence of target DNA. LOD and LQ values were 0.2 and $0.8 \mathrm{pM}$ ( 5 and $20 \mathrm{amol})$, respectively. The achieved LOD is 5.5 times lower than that obtained with the biosensor constructed by labeling the Ab $b_{\text {RNA/DNA }}$ with ProtAHRP (1.1 pM). Moreover the LOD achieved is similar to that reported previously with an electrochemical biosensor involving direct hybridization of a target DNA fragment with a specific 40-mer-b-RNACp immobilized onto Strep-MBs, recognition of the captured DNA/RNA heteroduplexes with the same AbrNA/DNA but labeling it with a ProtA conjugated with an homopolymer bearing 40 HRP molecules (ProtA-poly-HRP40) of $0.12 \mathrm{pM}$ for a $48 \mathrm{nt}$ synthetic target DNA (a specific fragment of the horse mitochondrial DNA D-loop region) (Ruiz-Valdepeñas Montiel et al., 2017b).

The relative standard deviation (RSD) value obtained from the amperometric measurements provided by 8 different biosensors prepared in the same manner for $25 \mathrm{pM}$ of the synthetic target DNA was $4.4 \%$, thus indicating a good reproducibility of the fabrication and amperometric transduction protocols involved.

The storage stability of the b-RNACp-MBs conjugates was tested after storing them at $4{ }^{\circ} \mathrm{C}$ in Eppendorf tubes containing $50 \mu \mathrm{L}$ of filtered $\mathrm{B} \& \mathrm{~W}$ buffer. Each working day, amperometric responses were measured for 0 and $10 \mathrm{pM}$ synthetic target DNA. No significant differences in the measured S/B ratio were apparent for a period of 69 days (no longer times were assayed), indicating an excellent stability of the b-RNACp-MBs conjugates.

\subsection{Selectivity}

The selectivity of this strategy was checked by comparing the amperometric responses obtained in the absence and in the presence of $10 \mathrm{pM}$ of the following synthetic sequences: target DNA, single mismatched (SM), double mismatched (DM), triple mismatched (TM) and non-complementary (NC). Fig. 4 shows as total discrimination was achieved against the NC sequence, while an acceptable selectivity was found against the mismatched sequences. The selectivity improved with the number of mismatched bases, showing a decrease in the amperometric responses obtained for the target DNA of 23, 40 and 50\% for the SM, DM and TM sequences, respectively. These results suggest 
the feasibility of the developed biosensors to discriminate even between the numbers of mismatches in the analyzed sequence.

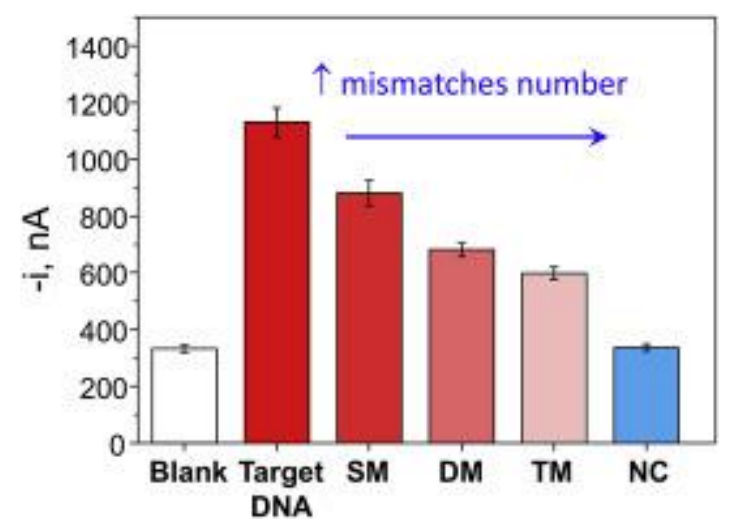

Fig. 4. Amperometric responses obtained with the biosensors constructed to determine the Sola 17 allergen coding sequence in the absence and in the presence of $10 \mathrm{pM}$ synthetic target DNA, SM, DM, TM and NC sequences. Amperometric detection made at $-0.20 \mathrm{~V}$ ( $v s$. Ag pseudoreference electrode) with SPCEs. Error bars were estimated as triple of the standard deviation $(n=3)$.

\subsection{Analysis of real samples}

The electrochemical biosensor constructed for the determination of the Sola 17 allergen coding sequence was applied to the analysis of $100 \mathrm{ng}$ of non-fragmented plant-derived genomic DNA extracts. It is worth to mention that a lower hybridization efficiency is expected considering the secondary and tertiary structures formed by such long targets which hinder an efficient hybridization to a surface-bound probe due to steric hindrance (Liu et al., 2007), (Cederquist and Keating, 2010).

Fig. 5 compares the results obtained with the biosensor for the measurements of the gDNA extracted from tomato (seeds and peel) and corn using two different protocols (CTAB or SDS-based methods). It is important to note that corn was selected for this study because it has an allergenic nsLTP, Zea m 14, which shows one of the highest percentages of identity and similarity in its primary sequence (amino acidic) with Sola 1 7. The $46 \%$ sequence identity and $64 \%$ similarity are higher than for the nsLTPs present in the skin of peach or apple. Both nsLTPs (Zea m 14 and Sola 17) come from seeds and if the developed biosensor does not recognize non-targeted Zea $m 14$ specific region, therefore it can be concluded that it would not recognize other nsLTPs with lesser sequence similarity. It is important to highlight also that corn and tomato can be consumed together in many processed foods (corn pancakes, purees, ketchup or pizza/pasta sauces) and that it has been reported that Zea m 14 and Sola 17 possess similar thermal stability and maintain their immunogenic capacity, triggering anaphylactic reactions, after severe processing at high temperatures for long periods of time (Pastorello et al., 2000), (Pastorello et al., 2003), (Guillen et al., 2014). As it is clearly seen, better results were achieved using the CTAB extraction protocol. In addition, only amperometric responses significantly different from the blank were obtained for gDNA extracted from the tomato seeds which is fully consistent with the specific location of the target nsLTP in this part of the fruit (Martín-Pedraza et al., 2016), thus demonstrating the high selectivity and sensitivity of the biosensor in these challenging samples. These important features can be attributed to the combination in the same methodology of the hybridization processes 
selectivity, the unique specificity of commercial antibodies for RNA heterohybrids and the use of MBs as solid supports for the affinity reactions to minimize matrix effects in complex samples (Tran et al., 2013), (Campuzano et al., 2017), (Serafín et al., 2017), (Ruiz-Valdepeñas Montiel et al., 2018). These results can be considered as highly relevant taking into account the much bigger length of the intact analyzed gDNA ( $792 \mathrm{Mbp})$ compared with the synthetic target (60-mer). Indeed, this gDNA is actually the longest target DNA detected to date with an electrochemical biosensor. In addition, this is the first electrochemical DNA sensor applied to perform the direct determination in intact genomic DNA extracted from plants (with smaller copies and a length $5 \times 10^{4}$ times longer than the horse mitochondrial DNA detected previously of $\sim 16 \mathrm{kbp}$ (RuizValdepeñas Montiel et al., 2017a, b)) without previous fragmentation or amplification and after just a denaturing step.

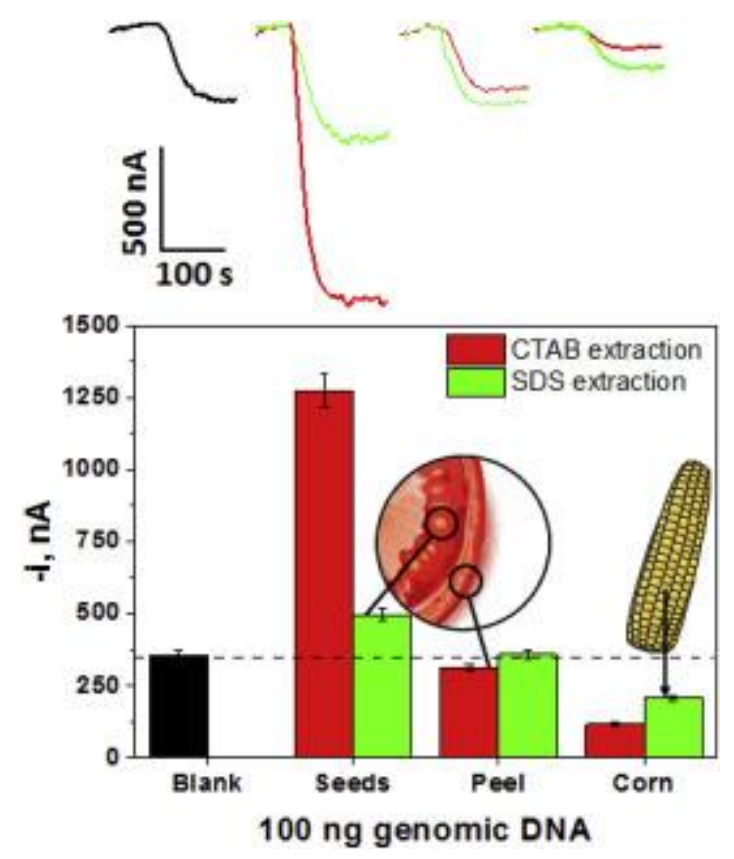

Fig. 5. Amperometric responses and amperograms measured with the biosensor constructed to determine the Sola 17 allergen coding sequence in the absence of target DNA (blank) and for $100 \mathrm{ng}$ of denatured gDNA extracted from tomato peel and seeds and corn. Amperometric detection performed at $-0.20 \mathrm{~V}$ ( $v s$. Ag pseudoreference electrode) with SPCEs. Error bars were estimated as triple of the standard deviation $(n=3)$.

\section{Conclusions}

This work reports the first disposable electrochemical nucleic acid sensors for the unequivocal detection of tomato seeds through the sensitive and selective PCR-free detection of a specific fragment of the characteristic Sola 17 allergen coding sequence. The developed biosensors exhibit a good sensitivity (LOD of $0.2 \mathrm{pM}, 5$ amol for the synthetic target) and selectivity and the analysis can be made in just $90 \mathrm{~min}$ with feasibility to be performed directly in $100 \mathrm{ng}$ of extracted raw gDNA without previous fragmentation and after a denaturing step. The excellent analytical performance of the implemented strategy without target nucleic acid amplification relies on the use of a sandwich hybridization assay leading to the formation of quite long RNA/DNA 
heteroduplexes and a commercial antibody with a high affinity to bind regions of only 6 $\mathrm{bp}$ in the RNA heterohybrids. The constructed biosensing platforms offer the possibility of tailoring the sensitivity by varying the bioassay format, heterohybrid length or labeling strategy. Moreover, these bioplatforms pave the way towards the sensitive detection of other nucleic acids regardless of their naturally occurring variety (DNA or RNA), origin (animal or plant), copy number (mitochondrial vs genomic) and length (from very long intact DNAs to degraded samples, difficult to be analyzed by conventional PCR-based methodologies), with no need for using nanomaterials or nucleic acid amplification. The simple handling of the biosensors with applicability at different settings and the relatively low cost per detection $(\sim 3.5 €)$ postulate these novel biotools as the basis for the electrochemical biosensing in routine analyses, even in locations where more complex laboratory equipment is not available, and with potential applications not only in food safety control and consumer protection but also in diagnostics, environmental monitoring, and genetic screening.

\section{Declaration of interest statement}

This work reports the first disposable electrochemical nucleic acid sensors for the unequivocal detection of tomato seeds through the sensitive and selective PCR-free detection of a specific fragment of the characteristic Sola 17 allergen coding sequence. The developed biosensors exhibit a good sensitivity (LOD of $0.2 \mathrm{pM}, 5$ amol for the synthetic target) and selectivity and the analysis can be made in just $90 \mathrm{~min}$ with feasibility to be performed directly in $100 \mathrm{ng}$ of extracted raw gDNA without previous fragmentation and after a denaturing step. The nice analytical performance of the implemented strategy without target nucleic acid amplification relies on the use of a sandwich hybridization assay leading to the formation of quite long RNA/DNA heteroduplexes and a commercial antibody with a high affinity to bind regions of only 6 bp in the RNA heterohybrids. The constructed biosensing platforms offer the possibility of tailoring the sensitivity by varying the bioassay format, heterohybrid length or labeling strategy. Moreover, these bioplatforms pave the way towards the sensitive detection of other nucleic acids regardless of their naturally occurring variety (DNA or RNA), origin (animal or plant), copy number (mitochondrial vs genomic) and length (from very long intact DNAs to degraded samples, difficult to be analyzed by conventional PCR-based methodologies), with no need for using nanomaterials or nucleic acid amplification. The simple handling of the biosensors with applicability at different settings and the relatively low cost per detection postulate these novel biotools as the basis for the electrochemical biosensing in routine analyses, even in locations where more complex laboratory equipment is not available, and with potential applications not only in food safety control and consumer protection but also in diagnostics, environmental monitoring, and genetic screening.

\section{CRediT authorship contribution statement}

Magda A. Pereira-Barros: Investigation. M. Fátima Barroso: Supervision, Writing original draft, Funding acquisition. Laura Martín-Pedraza: Investigation, Writing original draft. Eva Vargas: Investigation. Sara Benedé: Investigation, Writing - original draft. Mayte Villalba: Supervision, Funding acquisition. João M. Rocha: Supervision, Writing - original draft, Funding acquisition. Susana Campuzano: Supervision, Writing 
- original draft, Funding acquisition. José M. Pingarrón: Supervision, Writing - original draft, Funding acquisition.

\section{Acknowledgments}

The financial support of the Spanish Ministerio de Economía y Competitividad Research Projects, $\quad$ CTQ2015-64402-C2-1-R, $\quad$ SAF2017-86483-R and the TRANSNANOAVANSENS Program from the Comunidad de Madrid (Grant

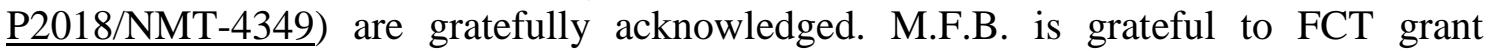
SFRH/BPD/78845/2011, financed by POPH-QREN-Tipologia 4.1-Formação Avançada, subsidized by Fundo Social Europeu and Ministério da Ciência, Tecnologia e Ensino Superior. The author M.A.P.B. is grateful to the authors J.M.R., M.F.B., S.C., J.M.P. for the scientific assistance and suggestions shared throughout the supervision of her Master's project and Master's thesis at University of Minho. The author M.A.P.B. also acknowledges the Department of Biology (DB) and the Centre of Molecular and Environmental Biology (CBMA) from University of Minho (UM), Braga, Portugal, by providing all the conditions leading to the Master's thesis in "Biophysics and Bionanosystems". Financial support of M.A.P.B. for this work was provided by a fellowship within the programme Erasmus+ scholarship/Portugal, which allowed performing the laboratorial work at the University Complutense of Madrid, Madrid, Spain. The author J.M.R. acknowledges CBMA-UM and DB-UM, Portugal, by the conditions provided. J.M.R. is also grateful to the Green Chemistry Laboratory (LAQV) - Research center Chemistry and Technology Network (REQUIMTE), and the Department of Chemistry and Biochemistry (DCB) from Faculty of Sciences, University of Porto (FCUP), Porto, Portugal, where currently he is researcher. J.M.R. acknowledges the financial support of the strategic programmes UID/BIA/04050/2013 (POCI-01-0145FEDER-007569) and PTDC/SAUNUT/30448/2017 (POCI-01-0145-FEDER-030448) and M.F.B. the financial support of the projects PTDC/QUI-QAN/30735/2017 and UID/QUI/50006/2019, funded by national funds through Fundação para a Ciência e Tecnologia [Foundation for Science and Technology] (FCT-I.P.)/Ministério da Ciência, Tecnologia e Ensino Superior [Ministry of Science, Technology and Higher Education] (MCTES), and Fundo Europeu de Desenvolvimento Regional [European Regional Development Fund] (FEDER), under the scope of the COMPETE2020 - Programa Operacional Competitividade e Internacionalização [COMPETE2020 - Competitiveness and Internationalization Operational Program, POCI]. S.B. acknowledges the financial support from MINECO through the "Juan de la Cierva" program. The authors have no conflicts of interest whatsoever to declare.

\section{References}

Ali et al., 2012

M.E. Ali, S. Mustafa, U. Hashim, Y.B. Che Man, K.L. Foo

J. Nanomater., 2012 (2012), p. 832387, 10.1155/2012/832387

Arlorio et al., 2007

M. Arlorio, E. Cereti, J.D. Coïsson, F. Travaglia, A. Martelli

Food Control, 18 (2007), pp. 140-148 
Asero, 2013

R. Asero

J. Investig. Allergol. Clin. Immunol., 23 (2013), pp. 37-42

Ballmer-Weber and Hoffmann-Sommergruber, 2011

B.-K. Ballmer-Weber, K. Hoffmann-Sommergruber

Curr. Opin. Allergy Clin. Immunol., 11 (2011), pp. 229-235

Barreda-García et al., 2015

S. Barreda-García, M.J. González-Álvarez, N. de los Santos-Álvarez, J.J. Palacios-Gutiérrez, A.J. Miranda-Ordieres

Biosens. Bioelectron., 68 (2015), pp. 122-128

Barreda-García et al., 2016

S. Barreda-García, R. Miranda-Castro, N. de los Santos Álvarez, A.J. MirandaOrdieres, M.J. Lobo-Castañón

Anal. Bioanal. Chem., 408 (2016), pp. 8603-8610

Barreda-García et al., 2017

S. Barreda-García, R. Miranda-Castro, N. de los Santos Álvarez, A.J. MirandaOrdieres, M.J. Lobo-Castañón

Chem. Commun., 53 (2017), pp. 9721-9724

Bassler et al., 2009

O.-Y. Bassler, J. Weiss, S. Wienkoop, K. Lehmann, C. Scheler, S. Dölle, D.

Schwarz, P. Franken, E. George, M. Worm, W. Weckwerth

J. Proteome Res., 8 (2009), pp. 1111-1122

Bettazzi et al., 2008

F. Bettazzi, F. Lucarelli, I. Palchetti, F. Berti, G. Marrazza, M. Mascinim

Anal. Chim. Acta, 614 (2008), pp. 93-102

Camacho et al., 2007

C. Camacho, J.C. Matías, B. Chico, R. Cao, L. Gómez, B.K. Simpson, R.

Villalonga

Electroanalysis, 19 (2007), pp. 2538-2542

Campuzano et al., 2017

S. Campuzano, P. Yánez-Sedeño, J.M. Pingarrón

Electrochim. Acta, 230 (2017), pp. 271-278

Cederquist and Keating, 2010

K.B. Cederquist, C.D. Keating

Langmuir, 26 (2010), pp. 18273-18280 
Eguílaz et al., 2010

M. Eguílaz, M. Moreno-Guzmán, S. Campuzano, A. González-Cortés, P. YáñezSedeño, J.M. Pingarrón

Biosens. Bioelectron., 26 (2010), pp. 517-522

Eissa et al., 2013

S. Eissa, L. L'Hocine, M. Siaj, M. Zourob

Analyst, 138 (2013), pp. 4378-4384

Gamella et al., 2012

M. Gamella, S. Campuzano, F. Conzuelo, A.J. Reviejo, J.M. Pingarrón

Electroanalysis, 24 (2012), pp. 2235-2243

Geroldinger-Simic et al., 2011

M. Geroldinger-Simic, T. Zelniker, W. Aberer, C. Ebner, C. Egger, A. Greiderer,

N. Prem, J. Lidholm, B.K. Ballmer-Weber, S. Vieths, B. Bohle

J. Allergy Clin. Immunol., 127 (2011), pp. 616-622

Guillen et al., 2014

D. Guillen, P. Barranco, A. Palacín, S. Quirce

Allergy Asthma Immunol. Res., 6 (2014), pp. 470-473

Holzhauser et al., 2014

T. Holzhauser, K. Kleiner, A. Janise, M. Röder

Food Chem., 163 (2014), pp. 68-76

$\underline{\text { Iniesto et al., } 2013}$

E. Iniesto, A. Jiménez, N. Prieto, B. Cabanillas, C. Burbano, M.M. Pedrosa, J.

Rodríguez, M. Muzquiz, J.F. Crespo, C. Cuadrado, R. Linacero

Food Chem., 138 (2013), pp. 1976-1981

Jirakova et al., 2019

L. Jirakova, R. Hrstka, S. Campuzano, J.M. Pingarrón, M. Bartosik

Electroanalysis (2019), 10.1002/elan.201800573

(in press)

Larramendi et al., 2008

C.-H. Larramendi, A. Ferrer, A.-J. Huertas, J.-L. Garcia-Abujeta, C. Andreu, R.

Tella, M.T. Cerdà, J. Bartra, J.R. Lavín, J.A. Pagán, M.A. López-Matas, E.

Fernández-Caldas, J. Carnés

Clin. Exp. Allergy, 38 (2008), pp. 169-177

Li et al., 2015

C. Li, Z. Liu, S. Cai, F. Wen, D. Wu, Y. Liu, F. Wu, J. Lan, Z. Han, J. Chen

Electrochem. Commun., 60 (2015), pp. 185-189 
Liu et al., 2007

W.-T. Liu, H. Guo, J.-H. Wu

Appl. Environ. Microbiol., 79 (2007), pp. 73-82

Liu et al., 2014

S.F. Liu, Y. Lin, T. Liu, C.B. Cheng, W.J. Wei, L. Wang, F. Li

Biosens. Bioelectron., 56 (2014), pp. 12-18

Martín-Pedraza et al., 2016

L. Martín-Pedraza, M. González, F. Gómez, N. Blanca-López, M. GarridoArandia, R. Rodríguez, M.J. Torres, M. Blanca, M. Villalba, C. Mayorga

Mol. Nutr. Food Res., 60 (2016), pp. 1172-1182

Mishra et al., 2018

G.K. Mishra, A. Barfidokht, F. Tehrani, R.K. Mishra

Foods, 7 (2018), p. 141, 10.3390/foods 7090141

Pastorello et al., 2000

E.A. Pastorello, L. Farioli, V. Pravettoni, M. Ispano, E. Scibola, C. Trambaioli,

M.G. Giuffrida, R. Ansaloni, J. Godovac-Zimmermann, A. Conti, D. Fortunato, C.J. Ortolani

J. Allergy Clin. Immunol., 106 (2000), pp. 744-750

Pastorello et al., 2003

E.A. Pastorello, C. Pompei, V. Pravettoni, L. Farioli, A.M. Calamari, J. Scibilia,

A.M. Robino, A. Conti, S. Iametti, D. Fortunato, S. Bonomi, C. Ortolani

J. Allergy Clin. Immunol., 112 (2003), pp. 775-783

Qavi et al., 2011

A.J. Qavi, J.T. Kindt, M.A. Gleeson, R.C. Bailey

Anal. Chem., 83 (2011), pp. 5949-5956

$\underline{\text { Ruiz-Valdepeñas Montiel et al., } 2016}$

V. Ruiz-Valdepeñas Montiel, A. Pellicanò, S. Campuzano, R.M. TorrenteRodríguez, Á.J. Reviejo, M.S. Cosio, J.M. Pingarrón

Sensor. Actuator. B, 236 (2016), pp. 825-833

Ruiz-Valdepeñas Montiel et al., 2017a

V. Ruiz-Valdepeñas Montiel, R.M. Torrente-Rodríguez, G. González de Rivera, A.J. Reviejo, C. Cuadrado, R. Linacero, F.J. Gallego, S. Campuzano, J.M. Pingarrón

Sensor. Actuator. B Chem., 245 (2017), pp. 895-902

Ruiz-Valdepeñas Montiel et al., 2017b

V. Ruiz-Valdepeñas Montiel, M.L. Gutiérrez, R.M. Torrente-Rodríguez, E. Povedano, E. Vargas, A.J. Reviejo, R. Linacero, F.J. Gallego, S. Campuzano, J.M. Pingarrón

Anal. Chem., 89 (2017), pp. 9474-9482 
$\underline{\text { Ruiz-Valdepeñas Montiel et al., } 2018}$

V. Ruiz-Valdepeñas Montiel, E. Povedano, E. Vargas, R.M. Torrente-Rodríguez, M. Pedrero, A.J. Reviejo, S. Campuzano, J.M. Pingarrón

ACS Sens., 3 (2018), pp. 211-221

$\underline{\text { Santiago-Felipe et al., } 2014}$

S. Santiago-Felipe, L.A. Tortajada-Genaro, R. Puchades, A. Maquieira

Anal. Chim. Acta, 811 (2014), pp. 81-87

Serafín et al., 2017

V. Serafín, R.M. Torrente-Rodríguez, M. Batlle, P. García de Frutos, S.

Campuzano, P. Yáñez-Sedeño, J.M. Pingarrón

Microchim Acta, 184 (2017), pp. 4251-4258

$\underline{\text { Sun et al., } 2012}$

X. Sun, L. Guan, X. Shan, Y. Zhang, Z. Li

J. Agric. Food Chem., 60 (2012), pp. 10979-10984

Torrente-Rodríguez et al., 2016

R.M. Torrente-Rodríguez, S. Campuzano, V. Ruiz-Valdepeñas Montiel, J.J. Montoya, J.M. Pingarrón

Biosens. Bioelectron., 86 (2016), pp. 516-521

$\underline{\text { Tran et al., } 2013}$

H.V. Tran, B. Piro, S. Reisberg, H.T. Duc, M.C. Pham

Anal. Chem., 85 (2013), pp. 8469-8474

$\underline{\text { Volpe et al., } 1998}$

G. Volpe, R. Draiscia, G. Palleschi, D. Compagnone

Analyst, 123 (1998), pp. 1303-1307

Zouari et al., 2018

M. Zouari, S. Campuzano, J.M. Pingarrón, N. Raouafi

Electrochim. Acta, 262 (2018), pp. 39-47

Zurzolo et al., 2012

G.A. Zurzolo, M.L. Mathai, J.J. Koplin, K.J. Allen

Curr. Allergy Asthma Rep., 12 (2012), pp. 292-296 